\title{
Evaluation of robot-guided minimally invasive implantation of 2067 pedicle screws
}

\author{
${ }^{*}$ Naureen Keric, MD, ${ }^{1}$ Christian Doenitz, MD, ${ }^{2}$ Amer Haj, MD, ${ }^{2}$ Izabela Rachwal-Czyzewicz, MD, ${ }^{3}$ \\ Mirjam Renovanz, MD, ${ }^{1}$ Dominik M. A. Wesp, MD, ${ }^{1}$ Stephan Boor, MD, ${ }^{3}$ Jens Conrad, MD, ${ }^{1}$ \\ Alexander Brawanski, MD, ${ }^{2}$ Alf Giese, MD, ${ }^{1}$ and Sven R. Kantelhardt, MD ${ }^{1}$
}

1Department of Neurosurgery and ${ }^{3}$ Institute of Neuroradiology, University Medical Centre, Johannes-Gutenberg University Mainz; and ${ }^{2}$ Department of Neurosurgery, University Hospital Regensburg, University of Regensburg, Germany

OBJECTIVE Recent studies have investigated the role of spinal image guidance for pedicle screw placement. Many authors have observed an elevated placement accuracy and overall improvement of outcome measures. This study assessed a bi-institutional experience following introduction of the Renaissance miniature robot for spinal image guidance in Europe.

METHODS The medical records and radiographs of all patients who underwent robot-guided implantation of spinal instrumentation using the novel system (between October 2011 and March 2015 in Mainz and February 2014 and February 2016 in Regensburg) were reviewed to determine the efficacy and safety of the newly introduced robotic system. Screw position accuracy, complications, exposure durations to intraoperative radiation, and reoperation rate were assessed.

RESULTS Of the 413 surgeries that used robotic guidance, 406 were via a minimally invasive approach. In 7 cases the surgeon switched to conventional screw placement, using a midline approach, due to referencing problems. A total of 2067 screws were implanted using robotic guidance, and 1857 screws were evaluated by postoperative CT. Of the 1857 screws, 1799 (96.9\%) were classified as having an acceptable or good position, whereas 38 screws (2\%) showed deviations of 3-6 mm and 20 screws $(1.1 \%)$ had deviations $>6 \mathrm{~mm}$. Nine misplaced screws, implanted in 7 patients, required revision surgery, yielding a screw revision rate of $0.48 \%$ of the screws and 7 of $406(1.7 \%)$ of the patients. The mean \pm SD per-patient intraoperative fluoroscopy exposure was $114.4( \pm 72.5)$ seconds for 5.1 screws on average and any further procedure required. Perioperative and direct postoperative complications included hemorrhage (2 patients, $0.49 \%$ ) and wound infections necessitating surgical revision (20 patients, $4.9 \%$ ).

CONCLUSIONS The hexapod miniature robotic device proved to be a safe and robust instrument in all situations, including those in which patients were treated on an emergency basis. Placement accuracy was high; peri- and early postoperative complication rates were found to be lower than rates published in other series of percutaneous screw placement techniques. Intraoperative radiation exposure was found to be comparable to published values for other minimally invasive and conventional approaches.

https://thejns.org/doi/abs/10.3171/2017.2.FOCUS16552

KEY WORDS robot-guided instrumentation; percutaneous; pedicle screw

$\mathrm{C}$ OMPARED with conventional fluoroscopic techniques, image guidance provides precise image reconstruction and an improved intraoperative visualization of critical structures, such as the human spine., ${ }^{1,24}$ When the surgical exposure is minimized, providing few or no identifiable anatomical landmarks, image guidance is of special value. ${ }^{1}$ Despite the lack of standardized evaluation methods and a generally accepted definition of screw misplacement, recent studies have consistently shown an improved accuracy of pedicle screw placement in image guidance series.

In their meta-comparison of navigation-assisted versus conventional screw placement covering 28 clinical, 14 cadaveric, and 1 model-based study, Tian et al. reported a higher overall accuracy of screw position in navigationassisted procedures. ${ }^{25}$ They reported a significantly lower

ABBREVIATIONS BMI = body mass index; PLIF = posterior lumbar interbody fusion; TLIF = transforaminal lumbar interbody fusion

SUBMITTED December 25, 2016. ACCEPTED February 20, 2017.

INCLUDE WHEN CITING DOI: 10.3171/2017.2.FOCUS16552.

* Drs. Keric and Doenitz contributed equally to this work. 
incidence of pedicle violations if navigation was applied, regardless of the system used. ${ }^{25}$

Similarly, in a meta-analysis reviewing pedicle screw placement accuracy following freehand versus imageguided procedures, Gelalis et al. observed a narrower interstudy range of screws fully contained within pedicles for CT navigation-supported procedures (89\%-100\%), when compared with freehand (69\%-94\%) and fluoroscopy-supported $(28 \%-85 \%)$ instrumentations. ${ }^{5}$

The accuracy of guidance systems in screw insertion procedures is particularly notable in anatomically difficult cases, such as scoliosis correction surgeries, with a reported 6-fold reduction in perforation rates and mean insertion angle errors compared with conventional methods. ${ }^{8,14}$

Similar to other navigation systems, miniature hexapod robots, such as Mazor's SpineAssist or Renaissance, provide intraoperative guidance and physically guide the surgeon along a preplanned trajectory. The Mazor system has been shown to improve surgical accuracy and, in combination with a minimally invasive approach, to minimize morbid sequelae and radiation doses for both patient and clinical staff in several studies. ${ }^{2,4,7,11,15,20,23,26}$ However, outcome data concerning the system's application in clinical routine and emergency cases are scarce.

Therefore, the purpose of this analysis was to assess the pedicle screw accuracy in robot-assisted procedures in daily clinical practice (elective and emergency operations). We provide a follow-up on the encouraging data from initial (pilot) studies., ${ }^{41,20}$ In addition, we evaluated the applicability and safety of the novel version of the robotic system (Renaissance). Furthermore, to our knowledge at the time of preparation, we present the largest consecutive bi-institutional series of robot-assisted spinal instrumentation procedures, with postoperative CT evaluation.

\section{Methods}

\section{Patient Sample and Study Design}

The medical records and radiographs of 406 consecutive patients who underwent spinal screw implantation under robotic guidance (Renaissance; Mazor Robotics, Ltd.) at 2 neurosurgical departments (Site 1, October 2011 to March 2015, and Site 2, February 2014 to February 2016) were retrospectively reviewed. Demographic, clinical, and diagnostic data, such as sex, age, personal history, levels of instrumentation, CT scan results, and data on the perioperative course were collected.

Screw position accuracy, complications, intraoperative radiation exposure duration, and reoperation rate were analyzed. Screw positioning was analyzed by a neurosurgeon and a neuroradiologist in patients with postoperative CT images and was categorized using a 5-point scale, as described by Wiesner et al. ${ }^{27}$ This classification ranges from Grades $0-4$, where Grade 0 represents a complete intrapedicular screw position, Grade 1 a cortical encroachment, Grade 2 an extrapedicular position of $<3 \mathrm{~mm}$, Grade 3 an extrapedicular deviation from 3 to $6 \mathrm{~mm}$, and Grade 4 a complete extrapedicular position or deviation of $>6$ $\mathrm{mm}$. Grades 0,1 , and 2 were considered as favorable and Grades 3 and 4 as misplaced results.

\section{Surgical Technique}

A preoperative CT scan (1-mm slice thickness) of the patient's spine was used to create a customized surgical plan, including optimization of trajectories and implant sizes. In the operating room, the guidance component was mounted on a specialized clamp, which was rigidly attached to the patient's spinous process. The CT-based blueprint was then matched to the patient's spine via 2 acquired fluoroscopic images (anteroposterior and oblique views) of the reference marker array and the spine. Following this matching process, the robot was guided to a target vertebral trajectory. Depending on the necessary work volume, 1 of 3 specialized arms was connected to the top of the robotic guidance unit. A cannula was placed through the arm, into which surgical tools and drills were inserted, guiding the surgeon to the planned trajectory. Posterior lumbar interbody fusion (PLIF)/transforaminal lumbar interbody fusion (TLIF) cages and decompression were performed when clinically indicated.

\section{Statistical Analysis}

All data are expressed as ordinal and nominal. Analyses are only presented for descriptive reasons and were regarded as explorative. Values are expressed as the mean \pm SD.

\section{Results}

\section{Patient Characteristics}

A total of 406 patients were included in this study. Detailed patient characteristics are displayed in Table 1. At Site 1, between October 2011 and March 2015, 318 patients underwent instrumentation of the thoracolumbar region. Nine patients were operated on using a freehand technique based on the surgeon's preoperative decision. Of the remaining 309 cases, 6 operations (1.9\%) were performed freehand due to failed registration of the robot, whereas 303 of those cases were performed under robotic guidance. The failed registration resulted from poor radiograph quality due to obesity (body mass index [BMI] > $35-40 \mathrm{mg} / \mathrm{kg}^{2}$ ) and/or severe osteopenia. Examples of intraoperative fluoroscopic images and correlating CT scans are shown in Fig. 1.

A postoperative CT scan of the operated spinal region was obtained in 259 of the 303 cases for assessment of implant position accuracy, according to the clinical standard protocol. In 44 patients, surgeons evaluated the screw position by an intraoperative C-OnSite scan, a technique for intraoperative $3 \mathrm{D}$ evaluation of pedicle screw positions using a conventional C-arm and novel software (Mazor Robotics). ${ }^{10}$ At Site 2, between February 2014 and February 2016, 104 patients underwent robot-assisted thoracolumbar instrumentation including PLIF procedures. Registration failure occurred in 1 patient due to obesity (BMI $40 \mathrm{mg} / \mathrm{kg}^{2}$ ). A postoperative CT scan was obtained in 100 patients for screw position accuracy assessment.

The mean age of all patients (Sites 1 and 2) was 65.8 years (range 20-89 years) and 221 of 406 patients were women (Table 1). The cohort presented with a spectrum of indications, including degenerative disease $(47.5 \%)$, infection $(21.7 \%)$, spondylolysis (11.3\%), trauma (7.9\%), osteoporotic fractures $(6.2 \%)$, and tumor $(5.4 \%)$. 
TABLE 1. Clinical characteristics of the study sample

\begin{tabular}{|c|c|c|c|}
\hline Characteristic & Total & Site 1 & Site 2 \\
\hline Age in yrs, mean (range) & $65.8(20-89)$ & $66(20-89)$ & $65.2(36-88)$ \\
\hline No. of pts $<45$ yrs & 30 & 22 & 8 \\
\hline No. of pts 45 to $<65$ yrs & 147 & 110 & 37 \\
\hline No. of pts $\geq 65$ yrs & 229 & 171 & 58 \\
\hline \multicolumn{4}{|l|}{ Sex, no. of pts } \\
\hline $\mathrm{F}$ & 221 & 174 & 47 \\
\hline M & 185 & 129 & 56 \\
\hline \multicolumn{4}{|l|}{ No. of pts w/ indication/mean age in yrs (range) } \\
\hline Degenerative & $193 / 65.4(35-88)$ & $128 / 65.4(35-85)$ & $65 / 66.1(36-88)$ \\
\hline Infection & $88 / 71.7(47-89)$ & $73 / 72(47-89)$ & $15 / 69.4(52-83)$ \\
\hline Spondylolysis & $46 / 57.4(21-84)$ & $26 / 57(21-84)$ & $20 / 58.2(37-82)$ \\
\hline Osteoporotic fractures & $25 / 74(47-84)$ & 25/74 (47-84) & $0 / 0$ \\
\hline Tumor & $22 / 60.5(21-82)$ & 20/61 (21-82) & $2 / 67(66-68)$ \\
\hline Trauma & $32 / 59.6(20-88)$ & $31 / 59(20-88)$ & $1 / 77$ \\
\hline \multicolumn{4}{|l|}{ No. of spinal instrumentations } \\
\hline Total thoracolumbar instrumentations & 422 & 318 & 104 \\
\hline Robot-guided instrumentations & 406 & 303 & 103 \\
\hline Primary conventional instrumentations & 9 & 9 & 0 \\
\hline Switch to conventional instrumentation & 7 & 6 & 1 \\
\hline Emergency cases & 27 of 406 & 27 of 303 & 0 \\
\hline \multicolumn{4}{|c|}{ Localization of robot-guided instrumentation, no. of pts } \\
\hline Thoracic & 58 & 52 & 6 \\
\hline Thoracolumbar & 27 & 24 & 3 \\
\hline Lumbar/lumbosacral & 220 & 161 & 59 \\
\hline Lumbosacral & 101 & 66 & 35 \\
\hline \multicolumn{4}{|l|}{ No. of instrumented levels } \\
\hline 1 & 261 & 188 & 73 \\
\hline 2 & 63 & 44 & 19 \\
\hline 3 & 63 & 60 & 3 \\
\hline 4 & 9 & 6 & 3 \\
\hline 5 & 10 & 5 & 5 \\
\hline \multicolumn{4}{|l|}{ Comorbidity (cardiovascular risk factors), no. of pts } \\
\hline Diabetes & 88 & 67 & 21 \\
\hline Coronary heart disease/heart insufficiency & 96 & 78 & 18 \\
\hline Pulmonary & 41 & 34 & 7 (COPD) \\
\hline \multicolumn{4}{|l|}{ Indication ASA score, mean \pm SD } \\
\hline Degenerative & $2.6( \pm 0.6)$ & $2.6( \pm 0.5)$ & $2.6( \pm 0.6)$ \\
\hline Infection & $2.9( \pm 1.2)$ & $3( \pm 1.2)$ & $2.5( \pm 0.5)$ \\
\hline Spondylolysis & $2.2( \pm 0.6)$ & $2.4( \pm 0.5)$ & $2( \pm 0.6)$ \\
\hline Osteoporotic fractures & $2.9( \pm 0.8)$ & $2.9( \pm 0.8)$ & 0 \\
\hline Tumor & $2.5( \pm 0.9)$ & $2.5(0.9)$ & $2.5( \pm 0.7)$ \\
\hline Trauma & $2.7( \pm 0.9)$ & $2.7( \pm 1)$ & 3 \\
\hline
\end{tabular}

ASA = American Society of Anesthesiologists; COPD = chronic obstructive pulmonary disease; pts = patients.

\section{Radiation Exposure and Screw Positions}

A total of 2067 screws were implanted spanning the T2-S2 region, averaging 5.1 screws per case. The mean operation time was 258.7 minutes per case $( \pm 105.6$ minutes) including decompression, PLIF, or TLIF procedures. The study involved a total mean per-patient intraopera- tive radiation exposure duration of 114.4 seconds $( \pm 72.5$ seconds), including the radiation associated with decompression, cage placement, and intraoperative evaluation of screw placement by C-OnSite scan (in 44 cases at Site 1; $\mathrm{C}$-OnSite was not available at Site 2). Of special note is that 27 of the procedures were performed outside of nor- 


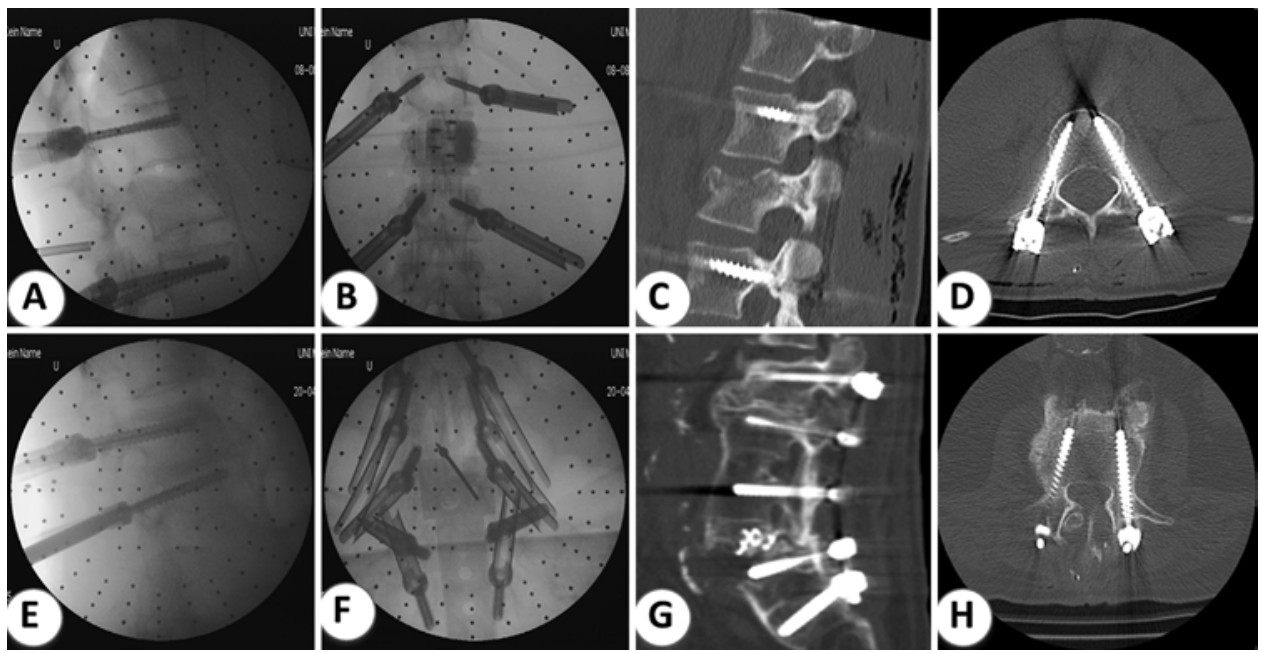

FIG. 1. Intraoperative fluoroscopic ( $A$ and $B$ ) and postoperative CT (C and D) images of a young woman with an L-4 fracture, illustrating good radiograph quality. Intraoperative fluoroscopic ( $E$ and $\mathbf{F}$ ) and postoperative $\mathbf{C T}(\mathbf{G}$ and $\mathbf{H})$ images of an obese patient with loosened implants in a degenerative spondylolisthesis, illustrating poor radiograph quality.

mal working hours on an emergency basis. These cases included 15 patients with lumbar spondylodiscitis, 7 with tumors, and 5 with trauma. The indication for an emergency surgery was mainly based on manifestation of a neurological deficit. This was caused by intraspinal empyema and fractured vertebra leading to spinal canal stenosis and paraparesis.

Postoperative CT imaging was performed in 359 patients, covering 1857 implanted screws. Image analysis demonstrated that $96.9 \%$ (1799) of the screw positions were classified as Grades 0, 1, or 2 (Grade 0: 83\% [1541]; Grade 1: $9 \%$ [167]; and Grade 2: $4.9 \%$ [91]), whereas 2\% (38) and 1.1\% (20) were Grades 3 and 4, respectively. One hundred thirty-eight screws were implanted in 27 emergency procedures (135 screws were Grades 0,1 , and 2; 2 screws were Grade 3; and 1 screw was Grade 4). Clinically significant screw deviations were mostly observed among patients who presented because of tumor disease ( 7 of 128 screws; $5.5 \%$ ), infection ( 22 of 431 screws; $5.1 \%$ ), and osteoporotic fractures (8 of 176 screws; 4.5\%) (Table $2)$. A by-level analysis of the screw position accuracy measures demonstrated that $13.2 \%$ of the screws placed in the upper thoracic spine (T1-6) were misplaced (Grades 3 or $4), 5.3 \%$ of the screws in the lower thoracic spine (T7-12)

TABLE 2. Indication versus incidence of Grade 3 and 4 screw positioning

\begin{tabular}{lccl}
\hline \multirow{2}{*}{\multicolumn{1}{c}{ Indication }} & \multicolumn{2}{c}{ No. of Grade 3/4 Screws (\%) } \\
\cline { 2 - 4 } & $13 / 738(1.7)$ & $11 / 484(2.3)$ & $2 / 254(0.8)$ \\
\hline Degenerative & $22 / 431(5.1)$ & $20 / 336(6.0)$ & $2 / 95(2.1)$ \\
\hline Infection & $8 / 176(4.5)$ & $8 / 176(4.5)$ & $0 / 0(0)$ \\
\hline Osteoporotic fractures & $1 / 166(0.6)$ & $1 / 92(1.1)$ & $0 / 74(0)$ \\
\hline Spondylolysis & $7 / 218(3.2)$ & $7 / 210(3.3)$ & $0 / 8(0)$ \\
\hline Trauma & $7 / 128(5.5)$ & $7 / 112(6.3)$ & $0 / 16(0)$ \\
\hline Tumor & $58 / 1857(3.1)$ & $54 / 1410(3.8)$ & $4 / 447(0.9)$ \\
\hline Total & & &
\end{tabular}

were misplaced, and $3.2 \%$ in the lumbosacral area were misplaced. In 26 patients, a single screw was misplaced; in 10 patients, 2 screws each were misplaced; and in 4 patients, 3 screws each were misplaced. The majority of the misplaced screws (38 of 58) showed a lateral deviation.

A detailed analysis of screw misplacement under robotic guidance revealed 3 main mechanisms. The most common misplacement typically resulted from so-called skiving (probably 28 screws; Fig. 2A). In 7 of 10 patients with 2 or 3 misplaced screws (total of 24 screws), CT analysis suggested an intraoperative platform dislocation (mechanisms shown in Fig. 2B and 2C). For the remaining 6 screw misplacements, the underlying mechanism was unclear.

We found no obvious correlation between the rate of misplaced screws and the operating surgeons' experience with the system.

\section{Clinical Course, Follow-Up, and Complications}

The mean follow-up at Site 1 was 75.5 days $( \pm 86.9$ days, in 303 patients), whereas we have only the data acquired during hospitalization for Site 2 (12.1 \pm 6.5 days, 103 patients). Within this period, 2 cases of hemorrhage were reported. Five patients $(1.24 \%)$ with 7 Grade 4 screws $(0.38 \%)$ and 2 patients $(0.49 \%)$ with an anterior vertebral perforation by 1 screw each $(0.1 \%)$ and contact with the abdominal aorta later required revision surgery, yielding a screw revision rate of $0.48 \%$ and an overall case revision rate due to misplaced screws of $1.7 \%$.

During the follow-up period, revision surgery was necessary in 7 cases (1.7\%) due to loosening and in 6 cases $(1.5 \%)$ due to dislocation (posthospitalization data from Site 1 only).

The mean hospital stay was 13.7 days ( \pm 9.1 days). Problems with wound healing were seen in 27 patients $(6.7 \%)$, and 20 of those patients needed revision surgery $(4.9 \%)$. In 26 cases $(6.4 \%)$, dural tears were seen, which all occurred during decompression/cage implantation. In 2 of these patients $(0.49 \%)$, a postoperative CSF-fistula and wound-healing problem led to revision surgery. In 4 


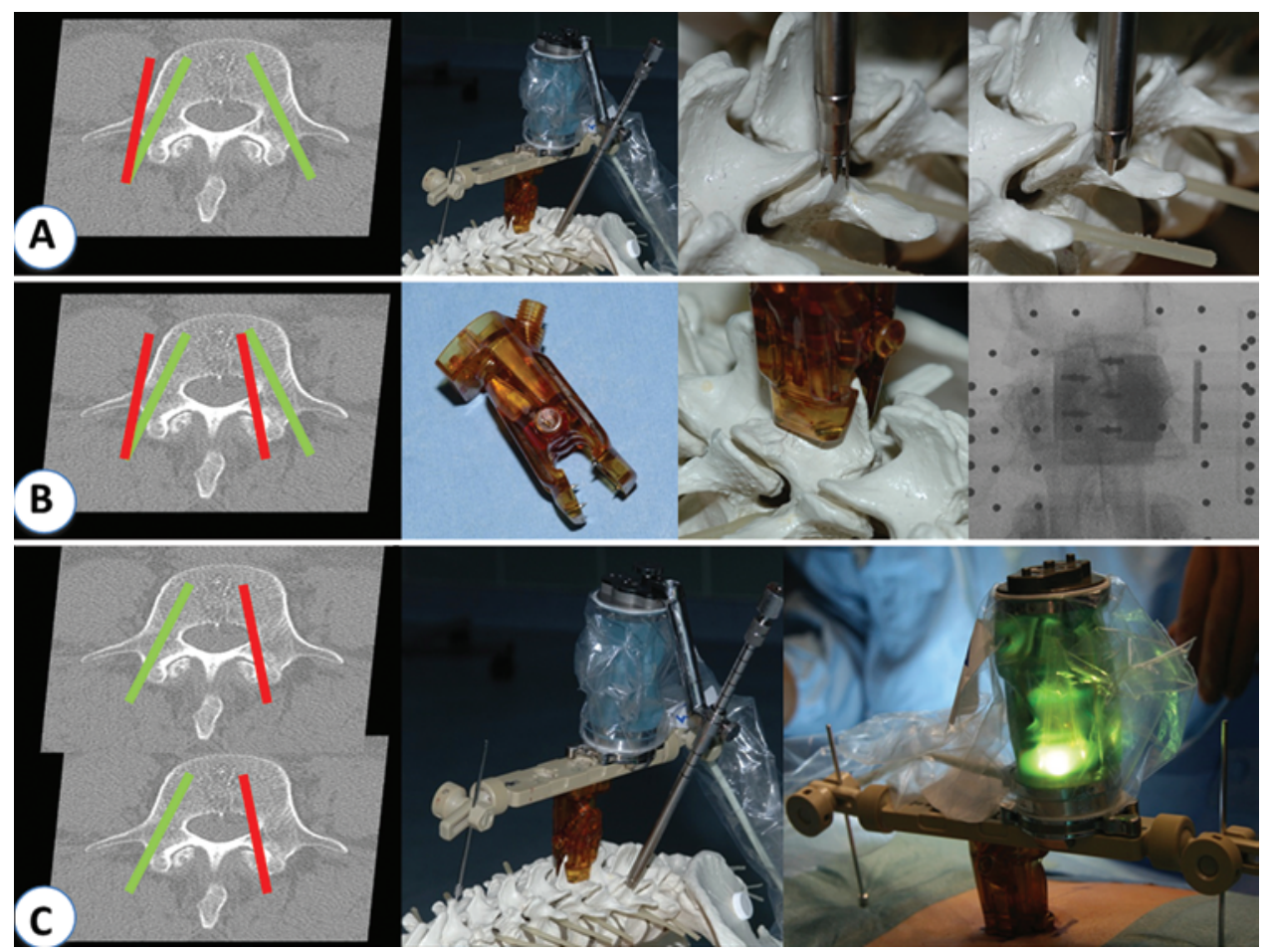

FIG. 2. Mechanisms of screw misplacement in robot-guided spinal instrumentation. A: An example of the most frequent intraoperative mechanism of screw misplacement by skiving at the entry point. The crown has to be firmly fixed at the entry point, which is marked by the perforating instrument beforehand. B: An illustration of the possible mechanism of clamp loosening during surgery. The first 2 screws in 1 vertebra are placed correctly and the next 2 screws in the following vertebra are misplaced. Photographs show the clamp for the spinous process, and an anteroposterior fluoroscopic image demonstrates a correctly fixed clamp. C: The example shows misplacement at 1 side, which may result from movements of the whole platform, e.g., the surgeon operates on both sides from 1 side and pushes or pulls the platform unknowingly; the platform is not additionally fixed with pins at the cranial or caudal edge. Photographs show the whole setup.

cases $(0.98 \%)$, new neurological deficits were postoperatively assessed. However, only 2 patients $(0.49 \%)$ required revision surgery: in 1 case of paraplegia due to an epidural thoracic hematoma and in 1 case of a nerve root injury due to a misplaced screw. Both patients immediately underwent reoperation and recovered incompletely. During the postoperative course, 4 patients suffered from pneumonia and 2 from pulmonary embolism. One patient had a myocardial infarction and died after a few days of intensive care therapy (Table 3).

\section{Discussion}

Visualization, planning, and placement of screws are indispensable when aiming to achieve optimal results in spine surgery. Recent studies have consistently shown the advantage of image guidance (e.g., robotic systems such as the Renaissance system) for the placement of pedicle screws with regard to accuracy.

In this study, we assessed the implications and applicability in clinical practice, as well as the clinical results and safety, of a miniature robotic system by analyzing the data obtained in patients who underwent elective and emergency procedures at 2 neurosurgical sites.

\section{Screw Placement}

Safety concerns related to pedicle screw placement have always been an issue, especially during the establishment of novel devices. When filtering screw placement accuracy by spine level, a clear advantage in accuracy has been achieved by using navigation deployment. In a systematic meta-analysis of pedicle screw instrumentation studies, pooling 37,337 screw placements, Kosmopoulos and Schizas reported consistently higher weighted mean screw placement accuracy for navigation-assisted screw placement compared with the unassisted procedures. ${ }^{13}$ More specifically, overall accuracy rates of $99.2 \%, 85.1 \%$, and $92.1 \%$ in the cervical, thoracic, and lumbar levels, respectively, were reported for navigation-assisted procedures versus $91.3 \%, 56.0 \%$, and $87.3 \%$, respectively, for non-navigated surgeries. ${ }^{13}$

The complexity of thoracic screw placement has also been expressed in a retrospective, observational study of thoracic screw placements $(n=279)$ in 40 consecutive patients, in which $43 \%$ of the screws demonstrated some degree of deviation. ${ }^{3}$ In this article, T1-4 screws were less likely to be fully confined within the pedicle/vertebral body than T9-12 screws. ${ }^{3}$ In his assessment of thoracic screw placement under 3D fluoroscopic guidance in cadavers, Holly also reported lower accuracy for thoracic screws $(92 \% ; n=59)$ compared with lumbar screws $(100 \%)$, where the mean pedicle diameter in which wall violations occurred was $4.6 \mathrm{~mm}$ compared with the mean $6-\mathrm{mm}$ diameter of all operated thoracic pedicles. ${ }^{6}$ The smaller pedicle 
TABLE 3. Outcome measures

\begin{tabular}{|c|c|c|c|c|}
\hline Outcome & Total & Site 1 & Site 2 & Details of the Whole Series \\
\hline Technical difficulties, no. & 7 of 413 & 6 of 309 & 1 of 104 & $\begin{array}{l}\text { Registration failure due to obesity }\left(\mathrm{BMI}>35-40 \mathrm{mg} / \mathrm{kg}^{2}\right) \& \text { poor } \\
\text { radiograph quality }\end{array}$ \\
\hline $\begin{array}{l}\text { Mean operation time per case, } \\
\quad \text { mins }( \pm S D)\end{array}$ & $258.7( \pm 105.6)$ & $267.5( \pm 111.3)$ & $232.2( \pm 76.8)$ & $\begin{array}{l}\text { Including registration for robot, screw implantation, decompres- } \\
\text { sion, PLIF \& TLIF procedures (\& C-OnSite scan in } 44 \text { cases) }\end{array}$ \\
\hline $\begin{array}{l}\text { Mean radiograph time per } \\
\text { case, secs }( \pm S D)\end{array}$ & $114.4( \pm 72.5)$ & $123.6( \pm 70.1)$ & $56.2( \pm 55.1)$ & $\begin{array}{l}\text { Including registration, screw implantation, PLIF \& TLIF proce- } \\
\text { dures (\& C-OnSite scan) }\end{array}$ \\
\hline Dural tears, no. $(\%)$ & $26(6.4)$ & $19(6.3)$ & $7(6.8)$ & $\begin{array}{l}\text { At decompression/cage implantation, } 2 \text { pts }(0.5 \%) \text { required } \\
\text { revision surgery }\end{array}$ \\
\hline $\begin{array}{l}\text { Wound healing abnormality, } \\
\text { no. }(\%)\end{array}$ & $27(6.7)$ & $25(8.3)$ & $2(1.9)$ & $\begin{array}{l}20 \text { (19 pts at Site } 1 \& 1 \text { pt at Site } 2 \text { needed wound revision } \\
[4.9 \%])\end{array}$ \\
\hline Hemorrhage, no. (\%) & $2(0.5)$ & $1(0.3)$ & $1(1)$ & $1 \mathrm{pt}(0.24 \%)$ required revision surgery \\
\hline $\begin{array}{l}\text { Revision op due to screw } \\
\text { misplacement, no. (\%) }\end{array}$ & $7(1.7)$ & $5(1.7)$ & $2(1.9)$ & $\begin{array}{l}5 \text { pts }(1.2 \%) \text { w/ } 7 \text { Grade } 4 \text { screws, } 2 \text { pts }(0.5 \%) \text { w/ anterior } \\
\text { vertebral perforation \& contact w/ abdominal aorta }\end{array}$ \\
\hline $\begin{array}{l}\text { Revision op due to screw loos- } \\
\text { ening/dislocation, no. (\%) }\end{array}$ & & $7(2.3) / 6(2.0)$ & & \\
\hline
\end{tabular}

diameters, variable morphology, and limited entry points in the mid- and upper thoracic regions have been suggested to be the source of lower mean accuracy rates observed for both assisted and unassisted thoracic screw placement procedures. ${ }^{6}$

When analyzing the misplaced screws per level in our study, the upper thoracic screws were more frequently misplaced, mostly resulting from skiving off when, for example, the ideal entry point was not chosen (Fig. 3A and B). Furthermore, in cases of very thin pedicles, a primarily in-out-in trajectory is recommended to avoid misplacement and pedicle fracture (Fig. 3C-F). When the ideal pedicle entry point technique is applied, thoracic pedicle screw placement accuracy in scoliotic spines has been reported to be as high as $93 \% .{ }^{17}$ By defining the base of the superior facet as the ideal pedicle entry point, rather than the commonly used transverse process and superior facet as landmarks, this technique has been shown to lower the incidence of pedicle violation. ${ }^{17}$

However, Kim et al. have claimed that diligent and repetitive confirmatory steps throughout freehand thoracic pedicle screw insertions yield reliable and safe placement results, even in deformed spines. ${ }^{12}$ Despite their reports of 10 of 577 thoracic screws $(1.7 \%)$ with a medial cortical wall violation $(2.5-5.0 \mathrm{~mm})$ and 26 of 577 screws exhibiting a lateral wall violation $(3.0-6.0 \mathrm{~mm})$, no neurological, vascular, or visceral complications were observed for up to 10 years after the procedure. ${ }^{13}$

The vast array of postoperative pedicle screw placement assessment methods complicates comparative analyses between studies. ${ }^{13}$ However, the present retrospective review, which evaluates screw placement accuracy in minimally invasive robot-guided spinal implantations, compares favorably with earlier reports of notable accuracy in imageguided minimally invasive spine procedures. In particular, the accuracies achieved in this study, in the upper (86.84\%) and lower (94.67\%) thoracic regions, were well above the reported mean accuracy rates for screws inserted using a freehand approach and slightly surpassed those reported for screws inserted by navigation-assisted techniques. Pos- sible mechanisms for screw misplacement in robot-guided spinal instrumentation are illustrated in Fig. 2.

A novel aspect of our series is that emergency cases were included, whereas most previous series recruited elective patients only. ${ }^{4,11,20} \mathrm{In}$ addition, this series represents the results achieved during routine clinical practice at both sites and provides longer follow-up than initial (pilot or feasibility) studies.

We found that the time used for preparation of a navigation plan was well spent, even in emergency situations, because the advantages (no accuracy loss) outweighed this time consumption.

\section{Complication Rates}

Complication rates associated with pedicle screw implantation are highly correlated with the primary indication, patient age, and procedural complexity. In a systematic literature-based review of complication rates in spinal surgery, Nasser et al. reported an overall complication incidence of $16.4 \%$ per patient, which was significantly higher in thoracolumbar (17.8\%) than cervical $(8.9 \%)$ procedures, where pseudarthrosis, hardware failure, radiculopathies, and infections were the most routinely reported complications following thoracolumbar procedures. ${ }^{18}$

In a retrospective review of prospectively collected data analyzing durotomy events in 108,478 surgical cases reported to the Scoliosis Research Society, an overall durotomy incidence of $1.6 \%$ was reported, with no differences between open versus minimally invasive procedures. Durotomy rates doubled in thoracic and lumbar procedures compared with the placement of cervical instrumentation for degenerative spinal disease and were also shown to significantly rise with patient age. ${ }^{28} \mathrm{~A}$ similar approach was taken to analyze surgical-site infection rates in 1338 minimally invasive spinal procedures, with demonstrated rates $(0.22 \%)$ that were significantly lower than those reported for open spinal surgeries $(0.7 \%-16 \%) .{ }^{19}$

We have previously shown that the selected approach 

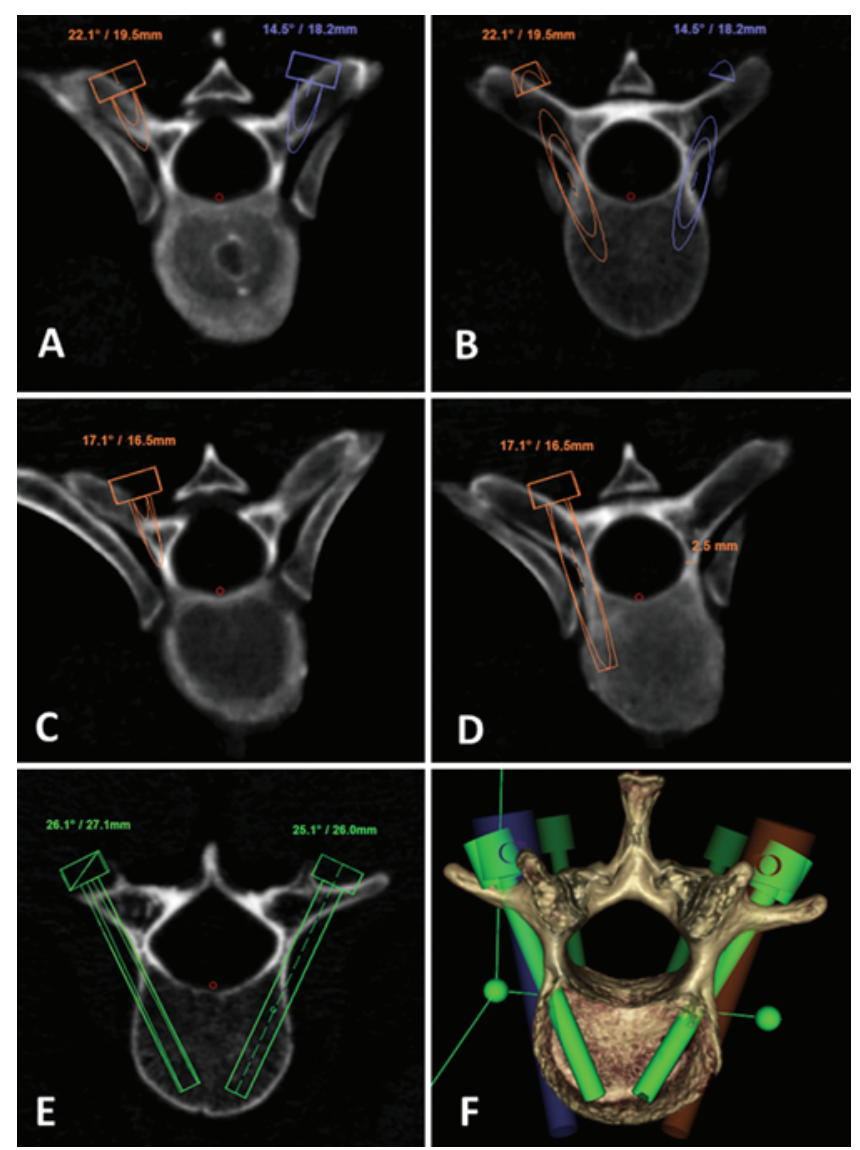

FIG. 3. A and B: Screenshots of a thoracic vertebra demonstrating the screw trajectory with a suboptimal entry point. C and D: Screenshots showing an example of an in-out-in trajectory planning in thin pedicles. E and F: Intraoperative screenshots of screws implanted via an in-out-in trajectory.

(open vs percutaneous) constitutes another important factor. ${ }^{11}$ Thus, despite the presented indications and advanced patient age in the present study, complication rates were comparably low, even when compared with other minimally invasive spine surgery cohorts. However, the mean operation time of 258.7 minutes ( \pm 105.6 minutes) seems long for a spinal instrumentation procedure with a mean of 5.1 screws per case.

The time periods for registration, screw placement, and PLIF/TLIF procedures were not assessed in detail in both centers during this case-collection study. Nevertheless, the registration process, which began after skin incision, was highly variable and could be very long compared with a fast and straightforward screw implantation after this step. This issue depended on different aspects, such as experience of staff handling the C-arm, patient's spinal anatomy, obesity, bone quality, and vertebral level.

\section{Radiation Exposure and Feasibility in Clinical Practice}

Although attempts have been made to intraoperatively assess pedicle screw positions without the application of radiation, the vast majority of centers use some type of fluoroscopic guidance or control. ${ }^{9,16}$ When considering the radiation associated with fluoroscopically-assisted pedicle screw placement procedures in cadavers, Rampersaud et al. reported an average of 8.5 fluoroscopic images required per screw, which was coupled with a mean exposure time of 9.3 seconds per screw. ${ }^{21}$ The highest dosimetry readings were detected by the unprotected waist badge and were similar to hand doses.

In a later clinical case series of computer-assisted 2D fluoroscopy in 161 percutaneous lumbosacral pedicle screw implantations, Ravi et al. reported an overall fluoroscopy time of 11-312 seconds (median 72 seconds) per case (mean 4 screws per patient). ${ }^{22}$ These data correlate rather well with the overall series; both centers involved noted a significant reduction of fluoroscopy times following introduction of the robotic system (as previously reported). ${ }^{11}$ However, the mean radiation times differed in both centers (Site 1, $123.6 \pm 70.1$ seconds; Site 2, $56.2 \pm 55.1$ seconds).

We found a correlation of surgical experience in spinal instrumentation with general and radiation times. At Site 1,10 different neurosurgeons contributed to this case series, but only 3 surgeons were experienced in conventional spinal instrumentation procedures. The other 7 neurosurgeons had no or minimal experience in conventional spinal instrumentation procedures. They primarily learned the robot-guided spinal instrumentation and needed a certain learning curve for interpretation of fluoroscopic images and the procedure itself, which consequently afforded longer radiation and operating times.

Two neurosurgeons were involved at Site 2. Again, the more experienced neurosurgeon used less radiation.

\section{Conclusions}

Robot-guided pedicle screw implantation using the hexapod miniature robot device is a safe and straightforward procedure. The system was successfully applied in 406 cases, whereas in 7 cases $(1.7 \%)$, the operating neurosurgeons switched to a conventional procedure. Lessons learned from 5.5 years of experience in using this guidance system in 2 neurosurgical departments are that meticulous preoperative planning and careful handling of the hardware are required to achieve highly accurate screw positioning.

Nevertheless, the system proved to be extremely reliable in all circumstances, including emergency cases. Screw deviations most frequently resulted from intraoperative problems with handling of the system, which led to the perpetuation of mistakes from skin incision to screw implantation. Limitations were observed in registration failure due to obesity (BMI > 35-40 mg/ $\mathrm{kg}^{2}$ ), osteoporosis, and consecutive poor radiograph quality (1.7\% of cases, as mentioned above).

Overall, this study demonstrated the notable accuracy of robot-guided, minimally invasive spinal instrumentation procedures. In addition, it documents the high reliability of the system in the daily surgical routine beyond initial studies.

\section{Acknowledgments} script.

We thank Prof. Florian Ringel for his help in revising the manu- 


\section{References}

1. Amr AN, Giese A, Kantelhardt SR: Navigation and robotaided surgery in the spine: historical review and state of the art. Robot Surg Res Rev 1:19-26, 2014

2. Barzilay Y, Schroeder JE, Hiller N, Singer G, Hasharoni A, Safran O, et al: Robot-assisted vertebral body augmentation: a radiation reduction tool. Spine (Phila Pa 1976) 39:153157,2014

3. Belmont PJ Jr, Klemme WR, Dhawan A, Polly DW Jr: In vivo accuracy of thoracic pedicle screws. Spine (Phila Pa 1976) 26:2340-2346, 2001

4. Devito DP, Kaplan L, Dietl R, Pfeiffer M, Horne D, Silberstein B, et al: Clinical acceptance and accuracy assessment of spinal implants guided with SpineAssist surgical robot: retrospective study. Spine (Phila Pa 1976) 35:2109-2115, 2010 [Erratum in Spine (Phila Pa 1976) 36:91, 2011]

5. Gelalis ID, Paschos NK, Pakos EE, Politis AN, Arnaoutoglou CM, Karageorgos AC, et al: Accuracy of pedicle screw placement: a systematic review of prospective in vivo studies comparing free hand, fluoroscopy guidance and navigation techniques. Eur Spine J 21:247-255, 2012

6. Holly LT: Image-guided spinal surgery. Int J Med Robot 2:7-15, 2006

7. Hu X, Scharschmidt TJ, Ohnmeiss DD, Lieberman IH: Robotic assisted surgeries for the treatment of spine tumors. Int J Spine Surg 9:1, 2015

8. Hu X, Siemionow KB, Liebermann ICH: Thoracic and lumbar vertebrae morphology in Lenke type 1 female adolescent idiopathic scoliosis patients. Int J Spine Surg 8:30, 2014

9. Kantelhardt SR, Bock CH, Larsen J, Bockermann V, Schillinger $\mathrm{W}$, Rohde $\mathrm{V}$, et al: Intraosseous ultrasound in the placement of pedicle screws in the lumbar spine. Spine (Phila Pa 1976) 34:400-407, 2009

10. Kantelhardt SR, Keric N, Conrad J, Nimer A, Woo R, Varich L, et al: C-OnSite ${ }^{\circledR}$ for intraoperative 3D control of pedicular screw positions. Acta Neurochir (Wien) 156:1799-1805, 2014

11. Kantelhardt SR, Martinez R, Baerwinkel S, Burger R, Giese A, Rohde V: Perioperative course and accuracy of screw positioning in conventional, open robotic-guided and percutaneous robotic-guided, pedicle screw placement. Eur Spine J 20:860-868, 2011

12. Kim YJ, Lenke LG, Bridwell KH, Cho YS, Riew KD: Free hand pedicle screw placement in the thoracic spine: is it safe? Spine (Phila Pa 1976) 29:333-342, 2004

13. Kosmopoulos V, Schizas C: Pedicle screw placement accuracy: a meta-analysis. Spine (Phila Pa 1976) 32:E111-E120, 2007

14. Kotani Y, Abumi K, Ito M, Takahata M, Sudo H, Ohshima $\mathrm{S}$, et al: Accuracy analysis of pedicle screw placement in posterior scoliosis surgery: comparison between conventional fluoroscopic and computer-assisted technique. Spine (Phila Pa 1976) 32:1543-1550, 2007

15. Kuo KL, Su YF, Wu CH, Tsai CY, Chang CH, Lin CL, et al: Assessing the intraoperative accuracy of pedicle screw placement by using a bone-mounted miniature robot system through secondary registration. PLoS One 7 11:e0153235, 2016

16. Maguire J, Wallace S, Madiga R, Leppanen R, Draper V: Evaluation of intrapedicular screw position using intraoperative evoked electromyography. Spine (Phila Pa 1976) 20:1068-1074, 1995

17. Modi H, Suh SW, Song HR, Yang JH: Accuracy of thoracic pedicle screw placement in scoliosis using the ideal pedicle entry point during the freehand technique. Int Orthop 33:469-475, 2009

18. Nasser R, Yadla S, Maltenfort MG, Campbell PG, Malone J: Complications in spine surgery. J Neurosurg Spine 14:1622,2011
19. O’Toole JE, Eichholz KM, Fessler RG: Surgical site infection rates after minimally invasive spinal surgery. J Neurosurg Spine 11:471-476, 2009

20. Pechlivanis I, Kiriyanthan G, Engelhardt M, Scholz M, Lücke S, Harders A, et al: Percutaneous placement of pedicle screws in the lumbar spine using a bone mounted miniature robotic system: first experiences and accuracy of screw placement. Spine (Phila Pa 1976) 34:392-398, 2009

21. Rampersaud YR, Foley KT, Shen AC, Williams S, Solomito M: Radiation exposure to the spine surgeon during fluoroscopically assisted pedicle screw insertion. Spine (Phila Pa 1976) 25:2637-2645, 2000

22. Ravi B, Zahrai A, Rampersaud R: Clinical accuracy of computer-assisted two-dimensional fluoroscopy for the percutaneous placement of lumbosacral pedicle screws. Spine (Phila Pa 1976) 36:84-91, 2011

23. Ringel F, Stüer C, Reinke A, Preuss A, Behr M, Auer F, et al: Accuracy of robot-assisted placement of lumbar and sacral pedicle screws: a prospective randomized comparison to conventional freehand screw implantation. Spine (Phila Pa 1976) 37:E496-E501, 2012

24. Roser F, Tatagiba M, Maier G: Spinal robotics: current applications and future perspectives. Neurosurgery 72 (Suppl 1): $12-18,2013$

25. Tian NF, Huang QS, Zhou P, Zhou Y, Wu RK, Lou Y, et al: Pedicle screw insertion accuracy with different assisted methods: a systematic review and meta-analysis of comparative studies. Eur Spine J 20:846-859, 2011

26. van Dijk JD, van den Ende RP, Stramigioli S, Köchling M, Höss N: Clinical pedicle screw accuracy and deviation from planning in robot-guided spine surgery: robot-guided pedicle screw accuracy. Spine (Phila Pa 1976) 40:E986-E991, 2015

27. Wiesner L, Kothe R, Schulitz KP, Rüther W: Clinical evaluation and computed tomography scan analysis of screw tracts after percutaneous insertion of pedicle screws in the lumbar spine. Spine (Phila Pa 1976) 25:615-621, 2000

28. Williams BJ, Sansur CA, Smith JS, Berven SH, Broadstone PA, Choma TJ, et al: Incidence of unintended durotomy in spine surgery based on 108,478 cases. Neurosurgery 68:117124,2011

\section{Disclosures}

The authors report no conflict of interest concerning the materials or methods used in this study or the findings specified in this paper.

\section{Author Contributions}

Conception and design: Keric, Doenitz, Giese, Kantelhardt. Acquisition of data: Keric, Doenitz, Haj, Rachwal-Czyzewicz, Wesp, Boor, Conrad. Analysis and interpretation of data: Keric, Doenitz, Haj, Rachwal-Czyzewicz, Renovanz, Wesp, Boor, Giese, Kantelhardt. Drafting the article: Keric, Doenitz, Renovanz, Conrad. Critically revising the article: Renovanz, Boor, Brawanski, Kantelhardt. Reviewed submitted version of manuscript: Brawanski, Kantelhardt. Statistical analysis: Keric, Doenitz. Study supervision: Brawanski, Giese, Kantelhardt.

\section{Supplemental Information \\ Previous Presentations}

Presented in part at the Annual Meeting of the German Society of Neurosurgery (DGNC), Karlsruhe, Germany, June 2015.

\section{Correspondence}

Naureen Keric, Department of Neurosurgery, University Medical Centre, Langenbeckstr. 1, Mainz 55131, Germany. email: naureen. keric@unimedizin-mainz.de. 